\title{
DESEMPENHO AGRONÔMICO DE CULTIVARES DE MILHO NOS PERÍODOS DE SAFRA E SAFRINHA ${ }^{(1)}$
}

\author{
ROGÉRIO FARINELLI ${ }^{(2,6)}$; FERNANDO GUIDO PENARIOL ${ }^{(2)}$; LUCIANO BORDIN $^{(3)}$; \\ LUCIANA COICEV $^{(4)}$; DOMINGOS FORNASIERI FILHO ${ }^{(5)}$
}

\begin{abstract}
RESUMO
O presente trabalho teve como objetivo avaliar o desempenho agronômico de cultivares de milho recomendadas para a Região Norte do Estado de São Paulo, nos períodos de safra e safrinha. Os experimentos foram desenvolvidos na Faculdade de Ciências Agronômicas e Veterinárias/UNESP, campus de Jaboticabal (SP), sendo o primeiro instalado na safrinha de 2000 e o segundo na safra de verão de 2000/2001. Em ambos foram semeados 15 cultivares comerciais, empregando-se o delineamento em blocos casualizados com três repetições, com parcelas experimentais representadas por quatro linhas de 5,0 metros cada uma. Os resultados mostraram que as condições ambientais influenciaram negativamente na produtividade na safrinha, e as cultivares DKB 440 e DKB 350 foram as mais produtivas. Os maiores valores de produtividade foram obtidos na safra, destacando-se as cultivares Dina 657 e AG 9090.
\end{abstract}

Palavras chaves: Zea mays, desenvolvimento, períodos de semeadura, híbridos.

\section{ABSTRACT \\ AGRONOMIC PERFORMANCE OF MAIZE CULTIVARS IN NORMAL AND LATE SEASON CROPS}

The experiment had the objective of evaluating agronomic performance of commercial maize cultivars, recommended for the northern part of the São Paulo state, in regular and late growing season. The experiments were carried out in the FCAV/UNESP, Jaboticabal campus, São Paulo state, Brazil, the first experiment being conducted in off season in 2000 and the regular second in the regular season of $2000 / 2001$. Fifteen commercial cultivars were sown in both experiments using a randomized-blocks design with three replications. The plots had 4 lines measuring 5 meters each. The results showed that environmental conditions reduced yield in off-season, the cultivars DKB 440 and DKB 350 being the most productive. The greatest yields were obtained in regular season, with Dina 657 and AG 9090 cultivars.

Key words: Zea mays, development, sowing dates, hybrids.

( $\left.{ }^{1}\right)$ Parte do Trabalho de Graduação do primeiro autor, apresentado à FCAV/UNESP, Jaboticabal (SP). Recebido para publicação em 25 de setembro de 2002 e aceito em 2 de abril de 2003. E-mail: rfarinelli@fca.unesp.br

(2) Pós-Graduação/Departamento de Produção Vegetal - FCA/UNESP, Caixa Postal 237, 18603-970 Botucatu (SP).

$\left.{ }^{3}\right)$ Departamento de Controle de Qualidade - Monsoy, Caixa Postal 112, 75650-000 Morrinhos (GO).

$\left({ }^{4}\right)$ Pós-Graduação/Departamento de Produção Vegetal - FCAV/UNESP, 14884-000 Jaboticabal (SP).

$\left(^{5}\right)$ Departamento de Produção Vegetal - FCAV/UNESP, Jaboticabal (SP).

$\left.{ }^{6}\right)$ Bolsista da CAPES. 


\section{Introdução}

O milho (Zea mays L.) é cultivado em grande parte do território brasileiro empregando-se diferentes sistemas de produção. Entretanto, segundo FORNASIERI FILHO (1992), sua eficiência de produção ainda é baixa, considerando o potencial do material genético disponível comercialmente.

Em virtude da grande quantidade de cultivares comerciais de milho (cerca de 150), da rapidez de sua substituição no mercado e da variabilidade de suas características agronômicas, técnicos e agricultores necessitam informações para a correta escolha de genótipos mais adequados às condições edafoclimáticas da sua região. Além disso, a grande dispersão da área cultivada em todo o Estado de São Paulo, ao redor de 800 mil hectares, e a heterogeneidade das condições ambientais e do nível tecnológico resultam em diversidade de ambientes e interferem no comportamento das cultivares entre as regiões (DuARte e Paterniani, 1999).

A estratificação de ambientes, a recomendação de cultivares aliada à densidade populacional e à adubação são fatores responsáveis para um bom desempenho da cultura, com possíveis ganhos de produtividade. Para cultivos de milho safrinha no Estado de São Paulo, sob condições de irrigação suplementar, a densidade populacional é a mesma recomendada para a safra normal - de 50 a 60.000 plantas.ha $^{-1}$; para cultivos sem irrigação, indicam-se reduções de $10 \%$ a $20 \%$, com espaçamento de $90 \mathrm{~cm}$ entre linhas,ou seja, de 33.333 a 44.444 plantas.ha $^{-1}$ respectivamente. Com relação à adubação nitrogenada em cobertura, Cantarella e Duarte (1997) e Cantarella (1999) concluíram que a resposta da cultura na safrinha varia com o tipo de solo, condições climáticas e patamares de produtividade; as doses mais econômicas situaram-se entre 30 e $40 \mathrm{~kg} \cdot \mathrm{ha}^{-1}$ de $\mathrm{N}$.

De acordo com Duarte e Paterniani (1998), a adaptação de cultivares a uma determinada região produtora varia com a época de semeadura de maneira que, em cultivos extemporâneos, as cultivares mais bem adaptadas não estão associadas com as da safra de verão. Assim, em áreas geográficas extensas, como a do Estado de São Paulo, a avaliação regionalizada de cultivares de milho, nos períodos de safra e safrinha, permite conhecer melhor os ambientes onde cada cultivar se sobressai e comparar suas vantagens e limitações nas diferentes regiões.

Este trabalho teve como objetivo avaliar o desempenho agronômico de cultivares de milho recomendadas para a Região Norte do Estado de São Paulo, nos períodos de safra e safrinha, no município de Jaboticabal (SP).

\section{Material e Métodos}

Os experimentos foram desenvolvidos na Faculdade de Ciências Agrárias e Veterinárias UNESP/Campus de Jaboticabal (SP), em Latossolo Vermelho Eutrófico, textura argilosa (EMBRAPA, 1999). O clima da região é do tipo Cwa, com precipitações pluviais mais elevadas em dezembro e menores em agosto, sendo a média anual de aproximadamente 1.400 mm (ANDRÉ e Volpe, 1982).

O sistema de preparo de solo empregado foi o convencional, mediante a utilização de arado escarificador e uma gradagem niveladora. A análise química do solo foi efetuada antes da instalação de cada experimento, de acordo com método descrito por RAIJ (1987). A adubação de semeadura seguiu as recomendações sugeridas por RAIJ et al. (1996) para a produtividade esperada de 8 a 10 t.ha $^{-1}$ para a safra e 4 a 6 t.ha $^{-1}$ para a safrinha, utilizando 250 e $200 \mathrm{~kg} \cdot \mathrm{ha}^{-1}$ da formulação 8-28-16+0,5\% Zn respectivamente.

Em ambos os experimentos foram utilizadas 15 cultivares de milho abrangendo materiais das principais empresas privadas, passíveis de utilização para a Região Norte paulista, descritos no quadro 1. O delineamento experimental empregado foi o de blocos casualizados com três repetições, e parcelas representadas por quatro linhas de $5,0 \mathrm{~m}$ de comprimento, espaçadas de $90 \mathrm{~cm}$ entre linhas (safrinha) e $80 \mathrm{~cm}$ entre linhas (safra), com uma densidade de semeadura de cinco plantas por metro linear. Considerou-se como parcela útil as duas linhas centrais.

As semeaduras foram realizadas em $17 / 3$ / 00 (safrinha) e 22/11/00 (safra). Aos 20 dias após a emergência realizou-se o desbaste para a obtenção da população inicial de 44.440 plantas.ha $^{-1}$ na safrinha e 57.500 plantas.ha $^{-1}$ na safra. As adubações de cobertura foram empregadas no estádio de 6 a 8 folhas desdobradas, com $40 \mathrm{~kg}$.ha ${ }^{-1} \mathrm{~N}$ e 90 kg.ha ${ }^{-1} \mathrm{~N}$, respectivamente, utilizando-se como fonte de $\mathrm{N}$ o sulfato de amônio.

Os tratos fitossanitários foram efetuados mediante aplicação de herbicidas e inseticidas, com produtos devidamente recomendados.

No campo, avaliaram-se as seguintes variáveis: altura média de plantas (medida do nível do solo até o ponto de inserção da última folha); altura média de espiga (medida do nível do solo até a inserção da primeira espiga) e florescimento masculino (através do método de graus-dia, determinando o subperíodo de emergência até o "pendoamento", com temperatura-base de $10{ }^{\circ} \mathrm{C}$, temperatura máxima menor ou igual a $32{ }^{\circ} \mathrm{C}$ e mínima maior ou igual a $10^{\circ} \mathrm{C}$ ). 
Quadro 1. Características agronômicas dos híbridos utilizados nos experimentos de safrinha ano 2000 e safra ano 2000/2001, em Jaboticabal (SP)

\begin{tabular}{lcccc}
\hline Cultivares & Ciclo & Tipo Híbrido & Grão & Finalidade de uso \\
\hline CO 32 & precoce & triplo & semiduro alaranjado & grão \\
AG 6690 & precoce & triplo & semiduro alaranjado & grão \\
Master & precoce & triplo & semido alaranjado & grão/silagem \\
CO 9560 & precoce & simples & semiduro amarelo/alaranjado & grão \\
C 333 B & semiprecoce & simples mod. & duro alaranjado & grão/silagem \\
Z 8550 & precoce & triplo & duro alaranjado & grão/silagem \\
Tork & precoce & simples & duro alaranjado & grão/silagem \\
C 747 & precoce & simples & semiduro alaranjado & grão \\
DKB 350 & precoce & simples & duro alaranjado & grão \\
Z 8420 & precoce & simples & semidentado amarelo & grão/silagem \\
DKB 440 & precoce & simples & semiduro amarelo/alaranjado \\
AG 8080 & precoce & triplo & semidentado alaranjado & grão/silagem \\
AG 9090 & precoce & triplo & semiduro alaranjado & grão \\
Dina 657 & precoce & simples mod. & semiduro alaranjado & grão \\
AG 9010 & superprecoce & simples mod. & & grão \\
\hline & & &
\end{tabular}

A colheita foi realizada manualmente, na área útil da parcela, tendo sido colhidas todas as espigas com palha. Posteriormente, avaliaram-se as demais variáveis: rendimento de espigas (através do peso de grãos e o peso total das espigas com palha); índice de espiga (através do número total de espigas e número de plantas); produtividade de grãos (obtido logo após a debulha das espigas). Calculou-se a produtividade final, em kg.ha- ${ }^{-1}$, após obtenção da massa de grãos por parcela, determinando-se o teor de água calculado em $13 \%$ de base úmida.

\section{Resultados e Discussão}

No período de safrinha, as cultivares apresentaram baixos valores médios de altura de plantas e de inserção da 1. a espiga (Quadro 2). A cultivar CO 9560 foi a que apresentou maior altura de planta e a maior altura de inserção da 1. ${ }^{a}$ espiga e Z 8550 apresentou o porte mais baixo. Os valores médios obtidos por Coicev (1998) na safrinha de 1998, para ambos os componentes fenológicos, foram similares aos do presente experimento. Tratam-se de valores inferiores aos obtidos, normalmente, na 1. ${ }^{\mathrm{a}}$ safra (das águas), em vista da influência das condições ambientais, sobretudo, em decorrência de baixas precipitações pluviais ocorridas durante o desenvolvimento da cultura.
Com relação à soma térmica no subperíodo emergência-florescimento masculino, o valor médio obtido foi de 871 unidades calóricas, tendo o híbrido C 333-B apresentado o maior acúmulo com 896 GD e o CO 9560 o menor valor, 856 GD.

O conhecimento do ciclo até o florescimento possui importância na escolha da cultivar e no planejamento da época de semeadura, de maneira que este estádio coincida com o período de menor probabilidade de ocorrência de déficit hídrico no solo. Segundo BRUNINI (1997), as semeaduras realizadas no período da safrinha, após o mês de fevereiro, fazem com que a planta de milho desenvolva a maior parte de seu ciclo em meses cuja taxa de acúmulo térmico de desenvolvimento diário é muito baixa, resultando em alongamento do ciclo.

Quanto à determinação dos componentes produtivos, o índice de espiga por planta variou entre 0,43 e 0,96 , com valor médio de 0,79 , o que caracteriza elevada quantidade de plantas sem espiga e predominância de cultivares não prolíficas.

As cultivares CO 9560 e DKB 440 foram as que mais se destacaram em relação ao rendimento de espiga; no entanto, a média geral de $60 \%$ foi menor do que a obtida por DuARTE et al. (1999) na safrinha de 1998, com valor médio de $83 \%$. 
Quadro 2. Valores médios de altura de plantas (AP), altura de inserção de primeira espiga (AE), graus-dia (GD), índice de espiga (IE), rendimento de espiga (RE) e produtividade de grãos em cultivares comerciais de milho no período de safrinha ano 2000, em Jaboticabal (SP)

\begin{tabular}{|c|c|c|c|c|c|c|}
\hline Cultivares & $\mathrm{AP}$ & $\mathrm{AE}$ & GD & IE & $\mathrm{RE}$ & Produtividade \\
\hline & $\mathrm{m}$ & $\mathrm{m}$ & $\mathrm{UC}$ & $\mathrm{n}^{\mathrm{o}} \cdot \mathrm{pl}^{-1}$ & $\%$ & kg.ha ${ }^{-1}$ \\
\hline $\mathrm{CO} 32$ & $1,57 \mathrm{abc}$ & $0,76 \mathrm{bcd}$ & 857 e & 0,93 a & $62 \mathrm{ab}$ & $1245 \mathrm{bcd}$ \\
\hline AG 6690 & $1,61 \mathrm{ab}$ & $0,76 \mathrm{bcd}$ & 863 cde & $0,73 \mathrm{ab}$ & $64 \mathrm{ab}$ & 931 de \\
\hline Master & $1,61 \mathrm{ab}$ & 0,86 a & 870 bcde & $0,93 \mathrm{a}$ & $63 \mathrm{ab}$ & $1287 \mathrm{bcd}$ \\
\hline CO 9560 & $1,66 \mathrm{a}$ & $0,86 \mathrm{a}$ & 856 e & $0,90 \mathrm{a}$ & $69 \mathrm{a}$ & $1358 \mathrm{abc}$ \\
\hline C 333 B & $1,39 \mathrm{fg}$ & 0,68 de & 896 a & $0,70 \mathrm{ab}$ & $63 \mathrm{ab}$ & 794 ef \\
\hline Z 8550 & $1,31 \mathrm{~g}$ & 0,69 cde & 863 cde & $0,70 \mathrm{ab}$ & $51 \mathrm{~d}$ & $492 \mathrm{f}$ \\
\hline Tork & $1,54 \mathrm{bcd}$ & $0,78 \mathrm{abc}$ & 860 de & $0,83 \mathrm{a}$ & $60 \mathrm{abc}$ & 753 ef \\
\hline C 747 & 1,51 bcdef & 0,74 bcde & 880 abcde & $0,76 \mathrm{ab}$ & $58 \mathrm{bcd}$ & 1133 bcde \\
\hline DKB 350 & 1,45 def & $0,66 \mathrm{e}$ & $884 a b c$ & 0,96 a & $63 \mathrm{ab}$ & $1485 \mathrm{ab}$ \\
\hline Z 8420 & 1,40 efg & 0,75 bcde & 860 de & $0,43 \mathrm{~b}$ & $57 \mathrm{bcd}$ & 929 de \\
\hline DKB 440 & 1,51 bcde & 0,75 bcde & 877 abcde & $0,93 \mathrm{a}$ & $68 \mathrm{a}$ & 1685 a \\
\hline AG 8080 & $1,57 \mathrm{abc}$ & 0,75 bcde & $888 \mathrm{ab}$ & $0,73 \mathrm{ab}$ & $50 \mathrm{~d}$ & 1080 cde \\
\hline AG 9090 & $1,52 \mathrm{bcd}$ & $0,66 \mathrm{e}$ & 867 bcde & $0,76 \mathrm{ab}$ & $65 \mathrm{ab}$ & $1329 \mathrm{abc}$ \\
\hline Dina 657 & 1,48 cdef & $0,83 \mathrm{ab}$ & 884 abcd & $0,63 \mathrm{ab}$ & $52 \mathrm{~cd}$ & 910 de \\
\hline AG 9010 & 1,50 bcdef & 0,69 cde & 863 cde & $0,90 \mathrm{a}$ & $63 \mathrm{ab}$ & $1368 \mathrm{abc}$ \\
\hline Média & 1,51 & 0,75 & 871 & 0,79 & 60 & 1118 \\
\hline Teste F & $18,01 * *$ & $12,94 * *$ & $7,55^{* *}$ & 3,96 ** & $11,55 * *$ & $17,95 * *$ \\
\hline CV (\%) & 2,52 & 4,17 & 0,91 & 15,96 & 4,89 & 11,6 \\
\hline
\end{tabular}

Médias seguidas de mesma letra, na coluna, não diferem entre si, pelo teste de Tukey a 1\% de probabilidade.

A produtividade de grãos permaneceu abaixo da estimada previamente, conseqüência das baixas precipitações ocorridas no período estudado, principalmente no estádio de florescimento masculino e enchimento de grãos, que podem ser comprovadas pelos dados da figura 1. A cultivar DKB 440 foi a mais produtiva, com $1.685 \mathrm{~kg} \cdot \mathrm{ha}^{-1}$.

DURÃES et al. (1995) ressaltam que as condições de cultivo de milho safrinha são desfavoráveis para o desenvolvimento da cultura, comparando-se com o período de primavera-verão, o que justifica a extrema importância na época de semeadura, por afetar principalmente o ciclo e a produtividade de grãos. CARAMORI et al. (1999), em estudo de zoneamento da cultura de milho safrinha, consideraram que o período mais sensível à deficiência hídrica corresponde a 15 dias antes e 15 após o florescimento masculino.

No quadro 3, verifica-se que no período de safra, a cultivar Master apresentou maior altura de planta, com 2,32 m, enquanto AG 9010 demonstrou menor altura de planta e de inserção da $1 .^{a}$ espiga, com valores de $1,86 \mathrm{~m}$ e $0,94 \mathrm{~m}$, respectivamente, caracterizando-a como um genótipo de grande capacidade de cultivo em populações adensadas e espaçamentos estreitos em virtude da disposição anatômica das folhas. Os valores médios obtidos para estes componentes foram superiores aos obtidos por DuARTE et al. (2000), que encontraram valores de 1,90 $\mathrm{m}$ e $0,97 \mathrm{~m}$ para a altura de plantas e inserção de $1 .{ }^{\mathrm{a}}$ espiga na Região Norte do Estado de São Paulo, na safra 1999/2000.

As cultivares C 333-B e DKB 440 destacaramse das demais, apresentando valores de 903 GD, em função do maior acúmulo térmico diário adquirido, devido ao incremento de temperatura nos meses anteriores ao "pendoamento". LozADA e ANGelocCi (1999), verificaram também que a temperatura média do ar apresentou efeito linear e quadrático sobre a duração do subperíodo de semeadura ao florescimento masculino, em valores entre $19,1^{\circ} \mathrm{C}$ e $25^{\circ} \mathrm{C}$. 
Quadro 3. Valores médios de altura de plantas (AP), altura de inserção de primeira espiga (AE), graus-dias (GD), índice de espiga (IE), rendimento de espiga (RE) e produtividade de grãos em cultivares comerciais de milho no período de safra ano 2000/2001, em Jaboticabal (SP)

\begin{tabular}{|c|c|c|c|c|c|c|}
\hline Cultivares & $\mathrm{AP}$ & $\mathrm{AE}$ & GD & IE & $\mathrm{RE}$ & Produtividade \\
\hline & $\mathrm{m}$ & $\mathrm{m}$ & UC & $\mathrm{n}^{\mathrm{o}} \cdot \mathrm{pl}^{-1}$ & $\%$ & kg.ha ${ }^{-1}$ \\
\hline $\mathrm{CO} 32$ & $2,16 \mathrm{~b}$ & $1,16 \mathrm{bc}$ & $864 \mathrm{~b}$ & $1,06 \mathrm{ab}$ & $81 \mathrm{a}$ & 8813 bc \\
\hline AG 6690 & $2,05 \mathrm{~cd}$ & $1,14 \mathrm{bc}$ & $891 \mathrm{ab}$ & $1,23 \mathrm{ab}$ & $65 \mathrm{a}$ & $10380 \mathrm{abc}$ \\
\hline Master & $2,32 \mathrm{a}$ & $1,43 \mathrm{a}$ & $881 \mathrm{ab}$ & $1,16 \mathrm{ab}$ & $77 \mathrm{a}$ & $10892 \mathrm{ab}$ \\
\hline CO 9560 & 2,09 bcd & $1,12 \mathrm{bcd}$ & $881 \mathrm{ab}$ & $1,00 \mathrm{ab}$ & $80 \mathrm{a}$ & 8870 bc \\
\hline C 333 B & $2,13 \mathrm{bc}$ & $1,12 \mathrm{bcd}$ & 903 a & $1,43 \mathrm{a}$ & 72 a & $11177 \mathrm{ab}$ \\
\hline Z 8550 & $2,05 \mathrm{~cd}$ & 1,07 cde & $864 \mathrm{~b}$ & $1,13 \mathrm{ab}$ & $80 \mathrm{a}$ & 9723 abc \\
\hline Tork & $2,12 \mathrm{bc}$ & $1,10 \mathrm{bcd}$ & $876 \mathrm{ab}$ & $1,43 \mathrm{a}$ & $82 \mathrm{a}$ & $10342 \mathrm{abc}$ \\
\hline C 747 & $1,99 \mathrm{de}$ & 1,05 cdef & $893 \mathrm{ab}$ & $1,16 \mathrm{ab}$ & $69 \mathrm{a}$ & $10331 \mathrm{abc}$ \\
\hline DKB 350 & $2,06 \mathrm{bcd}$ & $1,16 \mathrm{bc}$ & $898 \mathrm{ab}$ & $1,23 \mathrm{ab}$ & $77 \mathrm{a}$ & 9824 abc \\
\hline Z 8420 & 1,93 ef & $1,04 \mathrm{cdef}$ & $881 \mathrm{ab}$ & $1,06 \mathrm{ab}$ & 74 a & 8744 bc \\
\hline DKB 440 & $2,14 \mathrm{bc}$ & $1,01 \mathrm{def}$ & 903 a & $0,86 \mathrm{~b}$ & $80 \mathrm{a}$ & $7131 \quad \mathrm{c}$ \\
\hline AG 8080 & $2,07 \mathrm{bcd}$ & $1,15 \mathrm{bc}$ & $897 \mathrm{ab}$ & $1,26 \mathrm{ab}$ & $80 \mathrm{a}$ & $9593 a b c$ \\
\hline AG 9090 & 1,90 ef & 0,96 ef & $893 \mathrm{ab}$ & $1,40 \mathrm{a}$ & $64 \mathrm{a}$ & $11277 \mathrm{ab}$ \\
\hline Dina 657 & $2,06 \mathrm{bcd}$ & $1,20 \mathrm{~b}$ & 903 a & $1,26 \mathrm{ab}$ & 85 a & $12850 \mathrm{a}$ \\
\hline AG 9010 & $1,86 \mathrm{f}$ & $0,94 \mathrm{f}$ & 903 a & $1,40 \mathrm{a}$ & 81 a & $10133 \mathrm{abc}$ \\
\hline Média & 2,06 & 1,11 & 889 & 1,20 & 76 & 10000 \\
\hline Teste F & $28,31 * *$ & $25,68^{* *}$ & $4,32 * *$ & $3,50 * *$ & 1,94 & $4,40 * *$ \\
\hline CV (\%) & 1,81 & 3,58 & 1,25 & 12,81 & 10,34 & 11,05 \\
\hline
\end{tabular}

Médias seguidas de mesma letra, na coluna, não diferem entre si, pelo teste de Tukey a 1\% de probabilidade.

No entanto, verificaram que a duração desse subperíodo foi menor em virtude do acréscimo de temperatura. SANGOI (1993) observou que nas semeaduras realizadas em períodos de temperaturas mais elevadas, como por exemplo em novembro e dezembro, há maior velocidade nos processos metabólicos, acelerando o ciclo de desenvolvimento e reduzindo a duração dos períodos semeadura-emergência-pendoamento.

Quanto à avaliação dos componentes produtivos, as cultivares não apresentaram diferenças em relação ao rendimento de espiga, porém, o índice de espiga obtido foi da ordem de 1,20, e 'C 333-B' e 'Tork' mostraram valores semelhantes, correspondendo a 1,43 .

A produtividade de grãos obtida na safra foi alta, destacando-se a cultivar Dina 657, como a mais produtiva, com $12.850 \mathrm{~kg} \cdot \mathrm{ha}^{-1}$. Em virtude de a semeadura ter sido realizada em novembro, a alta produtividade foi provavelmente conseqüência das condições climáticas favoráveis, com volume maior de precipitações pluviais e temperaturas adequadas ocorridas durante o desenvolvimento das cultivares (Figura 1), de acordo com o estabelecido por AlFONSI et al. (1997). Esses autores notaram que, em plantios tradicionais em outubro, novembro e dezembro, o atendimento hídrico é mais provável, fazendo com que as fases fenológicas críticas da cultura do milho (florescimento e enchimento de grãos) coincidam com uma distribuição regular de chuvas.

A análise conjunta dos dados de produtividade nos períodos de safrinha e safra mostrou que os cultivares não diferenciaram significativamente entre si (Quadro 4). As cultivares Dina 657 e AG 9090 obtiveram as maiores médias (6.880 e $\left.6.303 \mathrm{~kg}^{\circ} \mathrm{ha}^{-1}\right)$. Analisando o Quadro 3, verifica-se que esses dois genótipos também apresentaram os maiores valores de produtividade na safra. Já o DKB 440 apresentou o menor resultado (4.408 kg.ha-1 $)$, mas na safrinha obteve a maior produtividade de grãos (Quadro 2). 


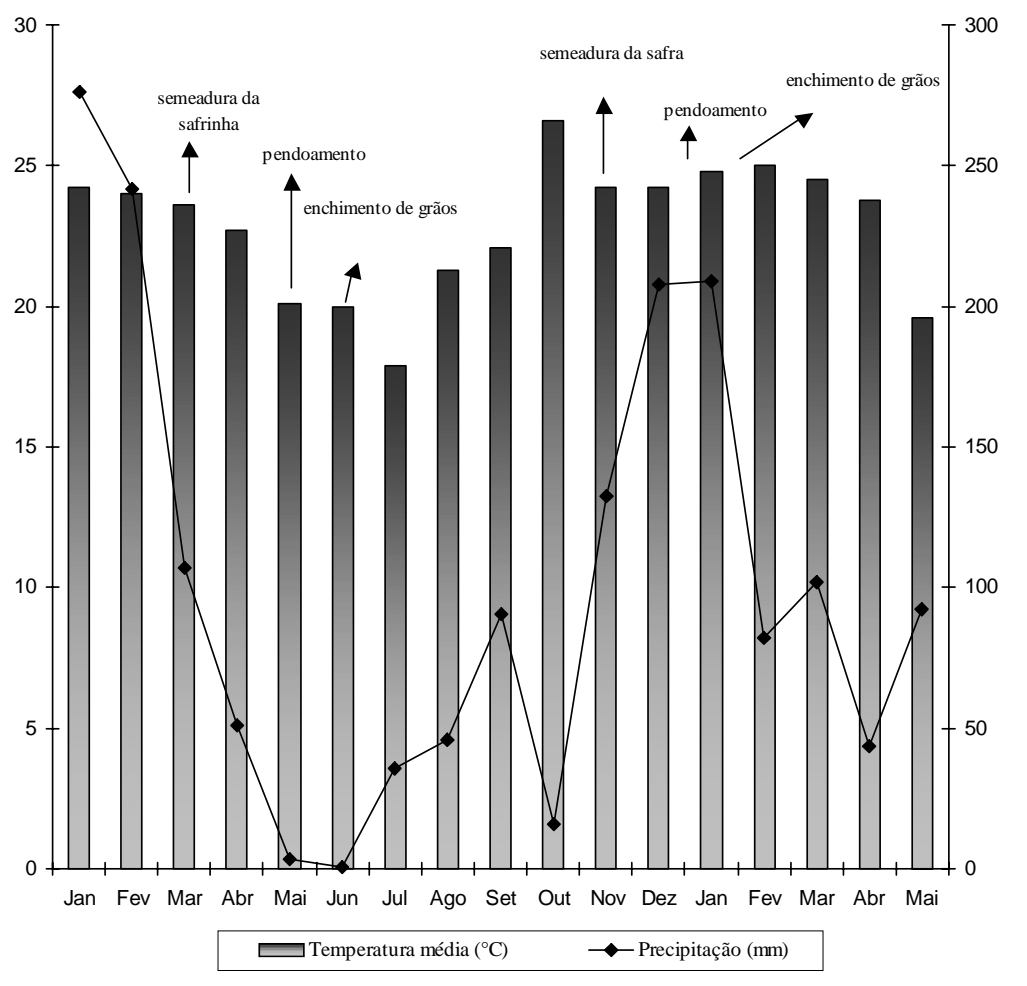

Fonte: Dados meteorológicos extraídos do acervo da área de Agrometeorologia do Departamento de Ciências Exatas, FCAV/UNESP.

Figura 1. Dados climáticos de temperatura média $\left({ }^{\circ} \mathrm{C}\right)$ e precipitação $(\mathrm{mm})$ nos estádios de desenvolvimento das cultivares de milho nos períodos de safrinha ano 2000 e safra ano 2000/2001, em Jaboticabal (SP).

Quadro 4. Análise conjunta da produtividade de grãos dos cultivares de milho no período de safrinha ano 2000 e safra ano 2000/2001, em Jaboticabal (SP)

\begin{tabular}{lc}
\hline Cultivares & Produtividade \\
\hline & 6880 a \\
Dina 657 & 6303 a \\
AG 9090 & 6089 a \\
Master & 5985 a \\
C 333 B & 5750 a \\
AG 9010 & 5732 a \\
C 747 & 5655 a \\
AG 6690 & 5654 a \\
DKB 350 & 5547 a \\
Tork & 5336 a \\
AG 8080 & 5114 a \\
CO 9560 & 5107 a \\
Z 8550 & 5029 a \\
CO 32 & 4836 a \\
Z 8420 & 4408 a \\
DKB 440 & 5562 \\
Média & $0,69^{\text {ns }}$ \\
Teste F & 19,01 \\
CV (\%) & \\
\hline
\end{tabular}

Médias seguidas de mesma letra, na coluna, não diferem entre si, pelo teste de Tukey a 1\% de probabilidade. 


\section{Conclusões}

1. O desempenho agronômico das cultivares na safrinha foi prejudicado pelas condições ambientais desfavoráveis caracterizadas pelo déficit hídrico e as baixas temperaturas nos estádios de florescimento masculino e enchimento de grãos, sendo 'DKB 440' e 'DKB 350' as mais produtivas neste período.

2. O cultivo de milho safrinha pode ser viável economicamente, desde que a semeadura seja realizada em períodos que apresentam maior disponibilidade hídrica e térmica. As semeaduras realizadas a partir de março, principalmente na Região Norte do Estado de São Paulo comprometem a produtividade, uma vez que a deficiência hídrica ocorre em praticamente todas as fases de desenvolvimento da cultura.

\section{Agradecimentos}

À Fazenda de Ensino e Pesquisa (FEP) da FCAV/UNESP, campus de Jaboticabal pela área concedida para as instalações e conduções dos respectivos experimentos no período de fevereiro de 2000 a maio de 2001.

À Fundação de Amparo à Pesquisa do Estado de São Paulo (FAPESP), pela bolsa de iniciação científica durante o desenvolvimento do trabalho de graduação.

\section{Referências Bibliográficas}

ALFONSI, R.R.; VICTORIA FILHO, R.; SENTELHAS, P.C. Épocas de semeadura para a cultura do milho no Estado de SP, baseadas na probabilidade de atendimento hídrico. Revista Brasileira de Agrometeorologia, Santa Maria, n5, p. 43-40., 1997.

ANDRÉ, R.G.B.; VOLPE, C.A. Dados meteorológicos de Jaboticabal no Estado de São Paulo, durante os anos de 1971 a 1980. Jaboticabal: FCAV, 1982. (Boletim Técnico).

BRUNINI, O. Probabilidade de cultivo do milho safrinha no Estado de São Paulo. In: SEMINÁRIO SOBRE A CULTURA DO MILHO SAFRINHA, 4., 1997, Assis. Resumos... Campinas: IAC/ Centro de Desenvolvimento Agropecuário do Médio Vale do Paranapanema, 1997. p. 37-53.

CANTARELLA, H. Adubação do milho "safrinha". In: "SEMINÁRIO SOBRE A CULTURA DO MILHOSAFRINHA", 5., 1999, Barretos. Curso para agricultores. Campinas: Instituto Agronômico, 1999. p.15-24.
CANTARELLA, H., DUARTE, A.P. Tabela de recomendação de adubação NPK para milho safrinha no Estado de São Paulo. In: "SEMINÁRIO SOBRE A CULTURA DO MILHO SAFRINHA", 4., 1997, Assis. Anais... Campinas: CATI/IAC/ IEA, 1997. p.65-70.

CARAMORI, P.H., WREGE, M.S., GONÇALVES, S.L. Zoneamento da cultura do milho "safrinha" e épocas de semeadura no Estado do Paraná. In: SEMINÁRIO SOBRE A CULTURA DO MILHO SAFRINHA, 5., 1999, Barretos. Resumos... Campinas: Instituto Agronômico, 1999. p.15-19.

COICEV, L. Avaliação de cultivares comerciais de milho nos períodos de "safrinha" e "normal" em Jaboticabal-SP. 1998. 71f. Monografia (Trabalho de graduação em Agronomia) - Faculdade de Ciências Agrárias e Veterinárias, Universidade Estadual Paulista, Jaboticabal.

DUARTE, A.P.; PATERNIANI, M.E.A.G.Z. (Coords.). Cultivares de milho no Estado de São Paulo: resultados das avaliações regionais IAC/CATI/EMPRESAS - 1997/98. Campinas: Instituto Agronômico, 1998. 81p. (Documentos IAC, 62).

DUARTE, A. P.; PATERNIANI, M. E. A. G. Z. (Coords.). Cultivares de milho no Estado de São Paulo: resultados das avaliações regionais IAC/CATI/EMPRESAS - 1998/99. Campinas: Instituto Agronômico, 1999. p.1-5 (Documentos IAC, 66).

DUARTE, A. P.; PATERNIANI, M. E. A. G. Z. (Coords.). Fatores bióticos e abióticos em estratificação ambiental: avaliação IAC/ CATI/EMPRESAS - 1999/00. Campinas: Instituto Agronômico, 2000. 150p. (Boletim Científico, 5).

DURÃES, F.O.M.; MAGALHÃES. P.C.; COSTA, J.D.; FANCELLI, A.L. Fatores ecofisiológicos que afetam o comportamento do milho em semeadura tardia ("safrinha") no Brasil central. Scientia Agricola, Piracicaba, v.52., p.491-591, 1995.

EMBRAPA. Centro Nacional de Pesquisa de Solos. Sistema Brasileiro de Classificação de Solos. Rio de Janeiro, 1999. 412p.

FORNASIERI FILHO, D. A cultura do milho. Jaboticabal:FUNEPFCAV, 1992. 273p.

LOZADA, B.I., ANGELOCCI, L.R. Efeito da temperatura do ar e da disponibilidade hídrica e na produtividade de um híbrido de milho. Revista Brasileira de Agrometeorologia, Santa Maria, v. 7, p. 37-43, 1999.

RAIJ. B. van. Análise química do solo para fins de fertilidade. Campinas: Fundação Cargill, 1987. 170p.

RAIJ, B. van.; CANTARELLA, H.;QUAGGIO, J.A.; FURLANI, A.M.C. Recomendações de adubação e calagem para o Estado de São Paulo. 2.ed. Campinas: Instituto Agronômico/Fundação IAC, 1996. p.60-61. (Boletim, 100).

SANGOI, L. Aptidão dos Campos de Lages (SC) para a produção de milho em diferentes épocas de semeadura. Pesquisa Agropecuária Brasileira, Brasília, v.8, p.51-63, 1993. 